\title{
Rift Valley fever in a zone potentially occupied by Aedes vexans in Senegal: dynamics and risk mapping
}

\author{
Cécile Vignolles ${ }^{1}$, Jean-Pierre Lacaux ${ }^{2}$, Yves M. Tourre ${ }^{3,4}$, Guillaume Bigeard ${ }^{2}$, \\ Jacques-André Ndione ${ }^{5}$, Murielle Lafaye ${ }^{1}$ \\ ${ }^{1}$ CNES, Toulouse, France; ${ }^{2}$ OMP, Université Paul Sabatier (UPS), Toulouse, France; ${ }^{3}$ METEO-France, \\ Direction de la Climatologie, Toulouse, France; ${ }^{4}$ LDEO of Columbia University, Palisades, NY, USA; \\ ${ }^{5}$ Centre de Suivi Ecologique (CSE) and Laboratoire de Physique de l'Atmosphère et de l'Océan, Université \\ Simon Fongang (LPAO-SF/ESP/UCAD), Dakar, Sénégal
}

\begin{abstract}
This paper presents an analysis of the interaction between the various variables associated with Rift Valley fever (RVF) such as the mosquito vector, available hosts and rainfall distribution. To that end, the varying zones potentially occupied by mosquitoes (ZPOM), rainfall events and pond dynamics, and the associated exposure of hosts to the RVF virus by Aedes vexans, were analyzed in the Barkedji area of the Ferlo, Senegal, during the 2003 rainy season. Ponds were identified by remote sensing using a high-resolution SPOT-5 satellite image. Additional data on ponds and rainfall events from the Tropical Rainfall Measuring Mission were combined with in-situ entomological and limnimetric measurements, and the localization of vulnerable ruminant hosts (data derived from QuickBird satellite). Since "Ae. vexans productive events" are dependent on the timing of rainfall for their embryogenesis (six days without rain are necessary to trigger hatching), the dynamic spatio-temporal distribution of Ae. vexans density was based on the total rainfall amount and pond dynamics. Detailed ZPOM mapping was obtained on a daily basis and combined with aggressiveness temporal profiles. Risks zones, i.e. zones where hazards and vulnerability are combined, are expressed by the percentages of parks where animals are potentially exposed to mosquito bites. This new approach, simply relying upon rainfall distribution evaluated from space, is meant to contribute to the implementation of a new, operational early warning system for RVF based on environmental risks linked to climatic and environmental conditions.
\end{abstract}

Keywords: remote sensing, Rift Valley fever, risk mapping, pond dynamics, rainfall distribution, early warning system.

\section{Introduction}

Rift Valley fever (RVF), an arthropod-borne disease which primarily causes epizootics of abortion and high mortality rate in domestic animals, can also infect humans. It is caused by a phlebovirus of the Bunyaviridae family, which engenders public health issues with a serious socio-economic impact in affected regions. For example, in Senegal, morbidity associated with RVF epidemics is on the rise (Ndione

Corresponding author:

Cécile Vignolles

CNES, DSP-ARP/AV, BPi 2902

18 Avenue Edouard Belin

31401 Toulouse Cedex 9, France

Tel./Fax +330561273345

E-mail: cecile.vignolles@cnes.fr et al., 2003). Epidemics result from the synergy of at least three factors which can vary considerably: (i) the presence and circulation of the phlebovirus by mosquito vectors; (ii) the number of mosquito breeding sites and hatching frequency, two parameters which are both highly dependent on environmental conditions, particularly rainfall events; and (iii) the distribution of domestic animal hosts, essentially ruminants (goats, sheep and cattle), vulnerable to increased vector/host contacts at night.

It has been shown that higher than average seasonal amount of rainfall in East Africa leads to a seasonal increase of vector-borne epidemics, including RVF (Linthicum et al., 1999) and malaria (Thomson et al., 2006). The strong correlation between RVF and the climate, and the influence of 
environmental variability are emphasized in the Ferlo region, Senegal. Indeed, this zoonotic arbovirosis has been emerging, and re-emerging, over West Africa where the confounding factors seem somewhat different to those in East Africa (Ndione et al., 2003). This paper concentrates on the mechanisms linking rainfall variability with the density of aggressive vectors, i.e. mosquitoes characterized by high numbers of bites/host/day. The investigation of these environmental risks took place in the Barkedji region of the Ferlo during the 2003 rainy season (Fig. 1). The abundance of RVF vectors such as Aedes vexans and Culex poicilipes (Meegan et al., 1989; Fontenille et al., 1998; Diallo et al., 2005) is directly linked to pond dynamics (Chevalier et al., 2004; Mondet et al., 2005a,b). The association of mosquito breeding sites with the filling-up and flushing-out of the ponds due to spatio-temporal variability of rainfall events has been pointed out by Ndione et al. (2003) and Bicout et al. (2003), among others, and depend on the mosquito species and their specific dynamics. For example, Ae. vexans lay their eggs along the pond edges where they mature and hatch only when more than six days of dry conditions are followed by total immersion from a rainfall event. From the entomological point of view such an event has been coined a "productive rainfall" since it favours mosquito breeding and hatching. For Ae. vexans, the following three conditions must be fulfilled for a "productive rainfall event":

(i) the amount of water from a single rainfall event

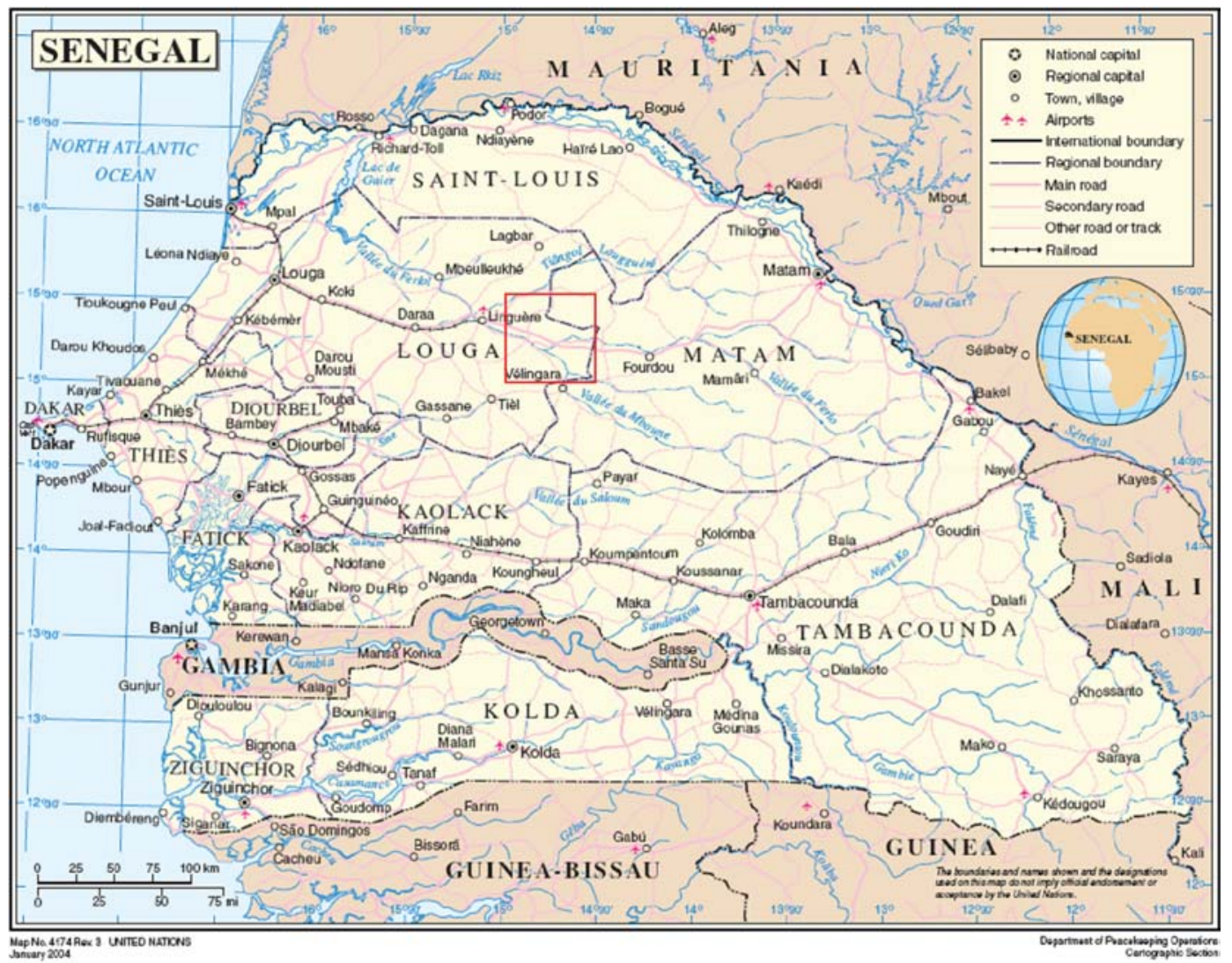

Fig. 1. Geography and study site. Ponds to be studied are located within the Barkedji window (red square) (from the Cartographic Section, DPKO, United Nations, NY, NY 10017). 
must reach at least of $10 \mathrm{~mm}$ (lower values did not affect ponds dynamic significantly, if at all, resulting in no or very little vector production);

(ii) a rainfall event delivering more than $10 \mathrm{~mm}$, must occur after a 6-day period without rain, the latter period being a necessary condition to trigger latent hatching; and

(iii) a rainfall event delivering more than $40 \mathrm{~mm}$, must occur after a 6-day period with less than $30 \mathrm{~mm}$ of rain.

Ae. vexans eggs can indeed survive in a dry environment up to a few months (Mondet et al., 2005a). Also specific to Ae. vexans, the virus can survive within the infected egg, i.e. until a productive rainfall as defined above occurs, thus leading to infected vectors directly (Lupi and Tyring, 2003). Cx. poicilipes, on the other hand, lays its eggs on the pond surface but these do not survive the dry conditions which often occur after a flushing event. Therefore, $C x$. poicilipes vectors usually appear during the apex of the rainy season when the ponds are well formed (Mondet et al., 2005b). The information given above is summarized and displayed in Figure 2a (Ndione et al., 2008, adapted from Bicout, 2001).

This paper refers only to the behaviour of Ae. vexans and it relies on earlier in-situ measurements made by entomologists. For example, it was learnt that the average Ae. vexans flying range is

a)

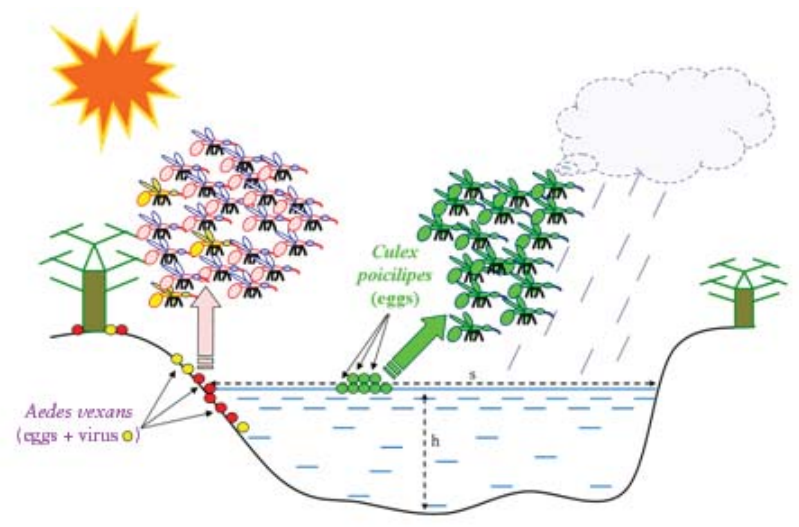

b)

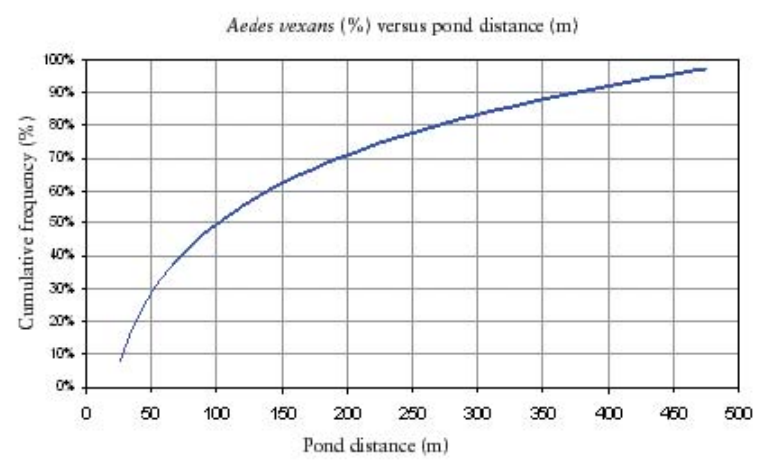

c)

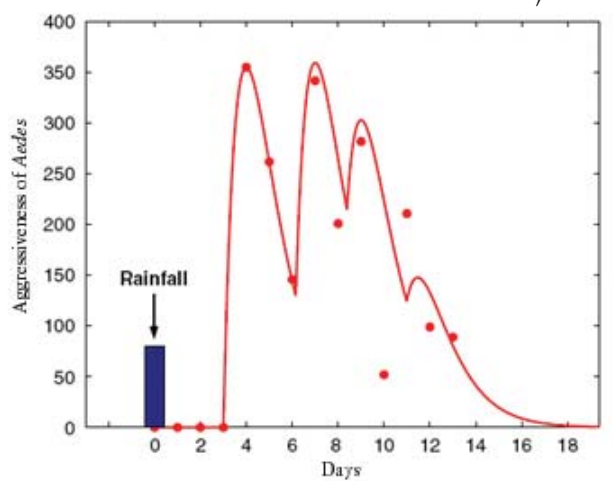

Fig. 2. Ponds and RVF vector mechanisms. a) Schematic ponds and breeding sites distribution. Ae. vexans eggs found around pond edges in red (in yellow when infected, i.e. vertical transmission). Cx. poicilipes eggs found mainly in open waters in green (these eggs are never infected by vertical transmission). The surface and depth of the ponds (which vary as a function of the rainy events) are denoted by "s " and "h"h", respectively. Note that only Ae. vexans is considered in this paper (after Ndione et al., 2008, adapted from Bicout, 2001). b) Cumulative Ae. vexans distribution in \% (ordinate), up to $500 \mathrm{~m}$ from a pond (abscissa), i.e. the zone with the highest serological incidence (after Bâ et al., 2005). c) Ae. vexans aggressiveness in days (abscissa) after a "productive rainfall event" (vertical blue bar) (after Ndiaye et al., 2006). 
such that their total number decreases linearly up to $500 \mathrm{~m}$ from a given pond. In addition, in Figure 2b, the cumulative density of Ae. vexans is displayed according to results by Bâ et al. (2005). The aggressiveness of Ae. vexans hatched after significant rainfall event (delivering at least $10 \mathrm{~mm}$ of rain) is a function of the number of days elapsed after the rainfall. This was studied by Ndiaye et al. (2006) who were able to estimate the daily total aggressiveness of Ae. vexans (nulliparous + parous) using a field population dynamics model with on-site validation. The first peak of aggressiveness by a nulliparous mosquito occurs about 4 days after a rainfall event, whilst second, third and fourth peaks from a parous one occur 8, 10 and 12 days, respectively, after the rainfall event. The total aggressiveness cycle lasts about 15 days after the rain event. The mean rainfall amounts needed to produce increased Ae. vexans populations, triggering an increased average aggressiveness, are displayed in Figure 2c (for details, see also Ndiaye et al., 2006).

Based on the observations and entomological studies discussed above and recent results by Lacaux et al. (2007) and Tourre et al. (2008), pond dynamics has been further evaluated after productive rainfall events in the Barkedji area during the 2003 rainy season. A schematic design of the integrated methodology to determine the environmental risk levels of RVF is presented in Figure 3. The upper left box in the figure identifies key entomological factors for Ae. vexans (flying-range, aggressiveness and embryogenesis), environmental factors (rainfall distribution, limnimetry and ponds dynamics) as well as pastoralist data such as the zones where animals are left for the night. From the upper right box, the detection of lead environmental and climatic factors (mainly rainfall) favouring the mechanisms presented in the box, are highlighted. For example, localization and optimal pond conditions for the breeding and hatching of Ae. vexans can be modelled. The central box refers to the zone potentially occupied by mosquitoes (ZPOM) derived from pond dynamics after a productive rainfall event including the flying ranges of Ae. vexans. The combination and integration of all the elements mentioned above lead to the notion of risks: hazards and vulnerability of host exposure. This original approach (CNES, 2008) bridges the physical and biological mechanisms, linking environmental conditions to the production of RVF vectors and the accompanying potential risks (Fig. 3).

Since the vulnerability to RVF depends upon the local agro-pastoral practices, dynamic ZPOMs thus contribute to the estimation of the ranked risks for animals of being bitten by the female Ae. vexans mosquito. The scales considered in this study amount to $10 \mathrm{~m}$ spatially and measurements occurred daily for the entire 2003 rainy season. The methodology used relies on rainfall distribution based on satellite data and the aim is to contribute to the development of an early warning system (EWS) for RVF based on environmental risks. The risks constitute the climatic and environmental conditions leading to potential RVF epidemics.

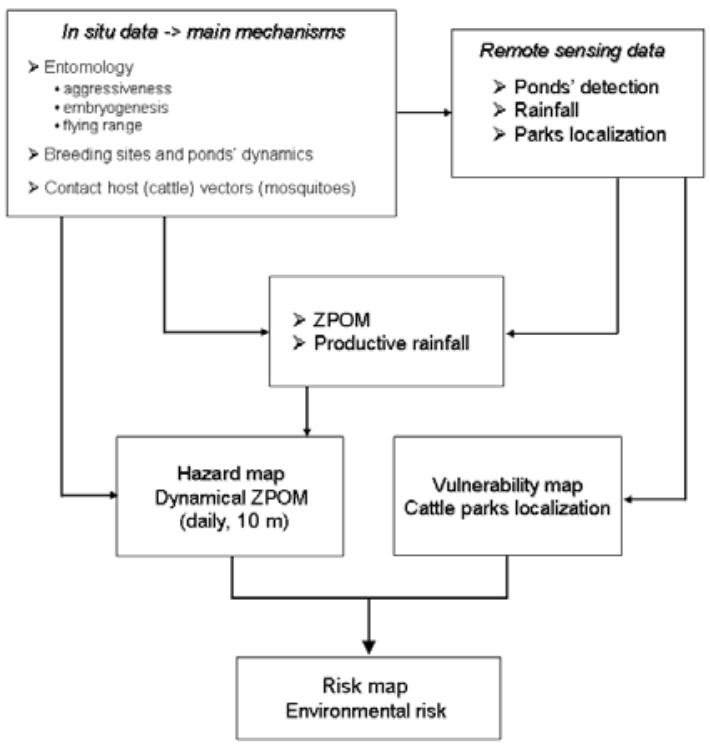

Fig. 3. Integrated methodology. The basic components for this study are presented in the top three boxes: in-situ data (upper left), remotely-sensed data (upper right), and ZPOM and productive rainfall (centre). The bottom three boxes distinguish between hazards (bottom left), vulnerability (bottom right), both leading to the environmental risks (very bottom). 


\section{Materials and methods}

\section{Entomological data}

All information about Ae. vexans pertain to the 2003 rainy season in the Barkedji area in the Ferlo region of Senegal. They include flying range data (courtesy of Bâ et al., 2005), daily aggressiveness data from Mondet et al. (2005a,b) and aggressiveness as modelled by Ndiaye et al. (2006).

Seven individual ponds with different environmental characteristics and eco-zones, namely Barkedji, Niakha, Ngao, Furdu, Kangaledji, Loumbel Lana and Yaralope, were studied in detail previously by Lacaux et al. (2007). Limnimetry, bathymetry and surface characteristics were followed during several rainy seasons (from 2002 to 2007). Relevant information about the depth (h), surface (s) and general features (with/without vegetation; turbid or not) of the ponds allowed us to establish linkages between rainfall events and pond dynamics (rates of filling-up and flushing-out). Furthermore, their surface variability and coverage (individually and clustered) led to remotely-sensed ZPOM mapping with uncertainties of $\pm 10 \%$ (maximum and minimum) according to Tourre et al. (2008).

\section{Hazard evaluation}

The degree of hazard was estimated following to Bicout et al. (2003), Bâ et al. (2005), and Ndiaye et al. (2006) and defined as the number of vectors per pixel for a given period of time. The scale was obtained from the relative maximum density of Ae. vexans mosquitoes, which is arbitrarily divided into seven equally distant aggressiveness classes stretching from absence of vectors (no hazard) to very high degrees of hazard. The latter is a function of ponds size and rainfall amount. Finally, starting with the lowest class of hazard (zero) and by adding classes two and three (i.e. very unlikely and very low hazard) together and classes four and five (i.e. low and moderate hazards) as well as joining classes six and seven (i.e. high and very high hazards), a final set of four hazard classes is obtained: zero, very unlikely, moderate and high. For example, between the two very unlikely and high classes, the highest hazards are $300 \%$ larger than those for the very unlikely class.

Judging from the observed vector aggressiveness (Fig. 2c), several time periods after each productive rainfall event can be considered as constituting high hazard: (i) the first 3-day period when nulliparous vectors can be infected (vertical transmission); and (ii) the following periods with much higher hazard (completed gonotrophic cycles) since the number of potentially infected bites increases considerably. Indeed, a single gonotrophic cycle is characterized by another blood meal during which the vector increases the risk of contamination.

\section{Remotely-sensed data}

SPOT-5 imagery allowed ponds detection in the Ferlo region of the Sahel using high-resolution ( 10 m pixels) images. Four spectral bands/channels were used, i.e. the green channel $(0.50$ to $0.59 \mu \mathrm{m})$, the red channel $(0.61$ to $0.68 \mu \mathrm{m})$, the near-infrared channel (NIR, 0.78 to $0.89 \mu \mathrm{m})$ and the mediuminfrared channel (MIR, 1.58 to $1.75 \mu \mathrm{m})$. Radiometric and geographic corrections, needed due to small changes in satellite altitude, inclination, position relative to the sun, curvature of earth, state of the troposphere, sensor calibration, were implemented by SPOT-Image. Digital counts (DCs) from radiometric values within each pixel, and "DC thresholds" from photo-interpretation were used for class ranking (for details, see Lacaux et al., 2007). The classification for each pixel was obtained by using a decision-tree classifier distinguishing between water and other soil elements. As such, new indices were developed, i.e. the normalized difference pond index (NDPI) and the normalized difference turbidity index (NDTI). Lacaux et al. (2007) provide details on how NDPI and NDTI were computed.

Data could be acquired at least every 26 days 
(orbital cycles of polar- and helio-synchronous satellites), with a revisit time of 3 days, assuming minimum cloud coverage, allowing detailed spatio-temporal evolution and dynamics of the ponds. The programmed five SPOT-5 images (60 x $60 \mathrm{~km}$ each) were centred near the Barkedji village in the Ferlo (Fig. 1), covering the 2003 rainy season in its entirety. This area is particularly suitable for the study since detailed entomological data, collected and analyzed previously (see above), contribute much to the understanding of the dynamics of the ponds considered as "vector producers". In addition, specific information on pond characteristics is available in Lacaux et al. (2007) and Tourre et al. (2008).

Among other parameters, the Tropical Rainfall Measuring Mission (TRMM) identifies rainfall events and estimates their amounts of water. TRMM, which has been in operation since January 1998 , is a joint space mission between NASA and the Japan Aerospace Exploration Agency (JAXA) designed to specifically monitor tropical rainfalls. The resulting data were downloaded from the http://disc2.nascom.nasa.gov/Giovanni/tovas/ website and averaged over the Barkedji area. As a working hypothesis, when few consecutive rainy days occurred, they were assimilated into one rainfall event (with the corresponding total rainfall amount). As discussed above, the presence and density of Ae. vexans mosquitoes are known to be governed by the frequency and intensity of rainfall as these events modify both the extent and the distribution of the ponds. The combined approach of ground checking and satellite monitoring takes into account not only the total amount of rainfall, but also the true accumulation of water within ponds and their extensions, all key parameters for mosquito production and ZPOM mapping.

Data from the QuickBird satellite, a high-resolution commercial earth-observation satellite launched in 2001, was used for geo-referencing only. Its panchromatic imagery is collected with a $0.6 \mathrm{~m}$ resolution and multi-spectral imagery at $2.4 \mathrm{~m}$ resolution. Details of structures such as areas fenced-in for animal keeping are thus easily visible with precise coordinates. The latter, embedded into the August 26, 2003 SPOT-5 image, allowed a precise mapping of the study area at that date. As a result, ZPOM mapping with pond dynamics includes all fenced-in areas where vulnerable animals were kept at night in the Barkedji area.

\section{Results}

Possible hazards in the vicinity of fenced-in hosts are displayed in Figure 4, where the Barkedji area is shown with the mapped ZPOMs. Thus, parks and villages can easily be identified. Out of 18 rainfall events obtained from TRMM for the 2003 rainy season, seven were considered as productive with regard to Ae. vexans production (based on entomological studies). Rainfall events (on July 20, 2003 and after September 5, 2003, respectively) did not qualify as productive, following the second criteria. The third criteria is well illustrated by the August 22, 2003 event which produced $64 \mathrm{~mm}$ rain in total,

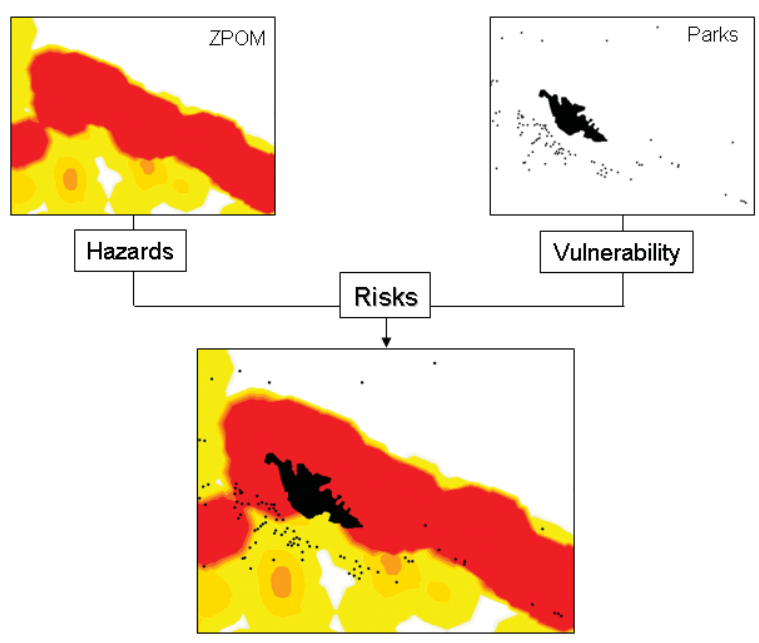

Fig. 4. Risks = hazards + vulnerability. ZPOMs with ranked risk. ZPOM in the Barkedji area judged from the pond distribution after a single rainfall event (top left). Localization of the Barkedji village and ruminants' fenced-in areas in black for the same area and time (top right). Possible risks are shown by super-imposing the two pictures (bottom). 
but was not counted as productive since the total amount of rainfall in the preceding 6-day period exceeded $30 \mathrm{~mm}$ (third criteria). The precise percentages for the 242 parks identified as being at risk during that same period are presented in Figure 5. Overall it can be said that from the seven productive rainfall events (vertical blue bars) $15 \%$ of the fenced-in ruminants were never at risk, whilst $60 \%$ to $30 \%$ of the fenced-in areas exposed the animals to moderate or high risk. One day out of three exposes $20 \%$ of fenced-in ruminants (and one day out of five exposes $30 \%$ ) to a very high risk.

The detailed dynamical evolution of ZPOMs during the full 2003 rainy season with associated risks is presented in the animated (see the on-line version) Figure 6 (an area of $17 \times 20 \mathrm{~km}$ ). Key dates, almost equally distributed during the season, are given starting on July 1, 2003. A total of 468 ponds were identified, which represent $1 \%$ of the study area (the size of $80 \%$ of the individual ponds were less than 0.5 ha, whilst $2.3 \%$ were larger than 5 ha).

\section{Discussion and conclusion}

Environmental risks are constituted of mechanisms linking rainfall variability, density of vectors and their aggressiveness, with hosts vulnerability. The dynamical evolution of ZPOMs, with ranked risks (colour coded) from the ponds in the Barkedji area, has identified risk as a function of discrete and productive rainfall events which dramatically displays the socio-economic problems to which populations of the region are exposed.

From Lacaux et al. (2007) and Tourre et al. (2008), and the results of this paper, rainfall events indeed appear to be the confounding factor for Ae. vexans proliferation, since the water directly modifies the size and clustering of the ponds. Resulting ZPOMs and spatial dynamic variability are found to be directly linked to these rainfall events (mainly squall-lines). Based upon ponds distributed within the Barkedji zone (including a fossil river site), a new, integrated methodological

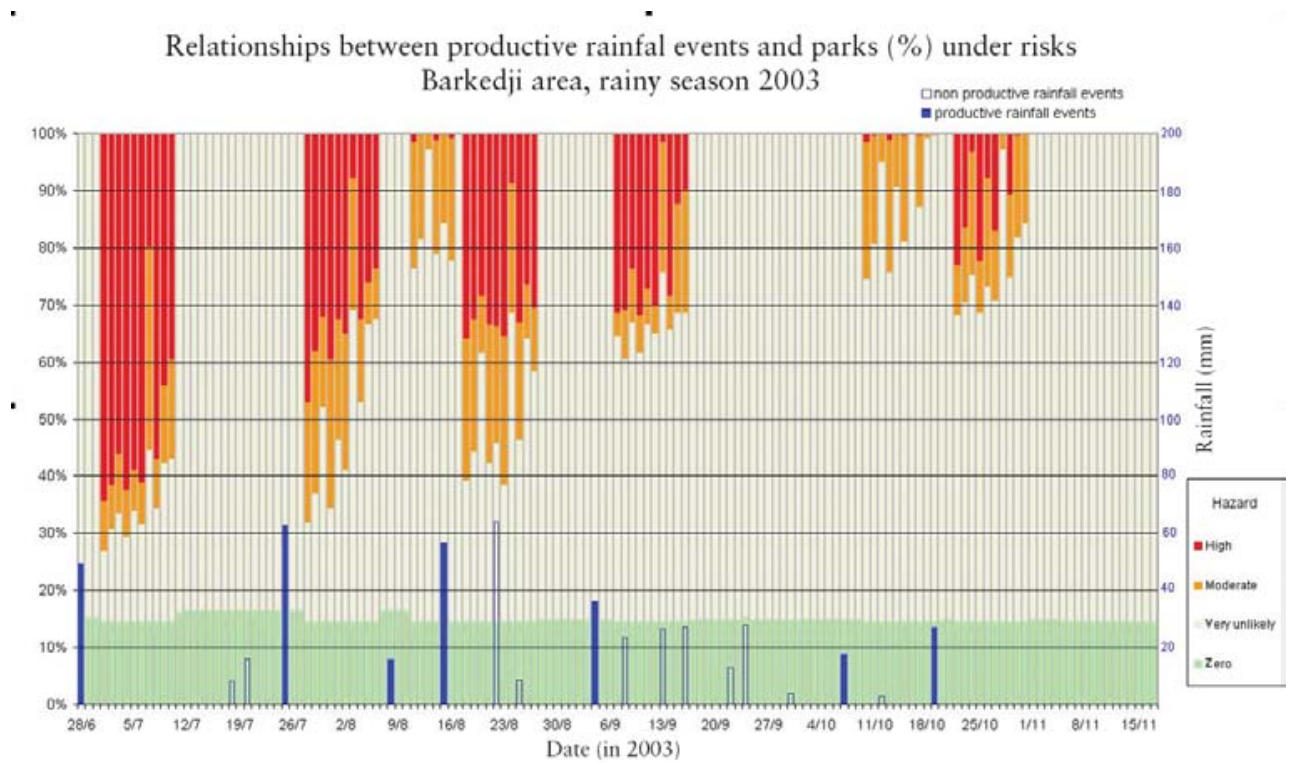

Fig. 5. Rainfall events and RVF environmental risks. From TRMM data rainfall events and amounts (in mm, right ordinates) over the Barkedji area (17 km x $20 \mathrm{~km}$ ) during the 2003 rainy season. Timing (in date, on the abscissa) of rainfall events shown as blue bars when the event was productive with regard to Ae. vexans (seven of the 18 events for the full period) and as white bars when non-productive. From the 242 ruminants' fenced-in areas geo-referenced using QuickBird, percentages of areas (left ordinates) with possible RVF hazards computed using dynamic ZPOM. The hazard scale shown as a spectrum from high risk (red) to none (green). 


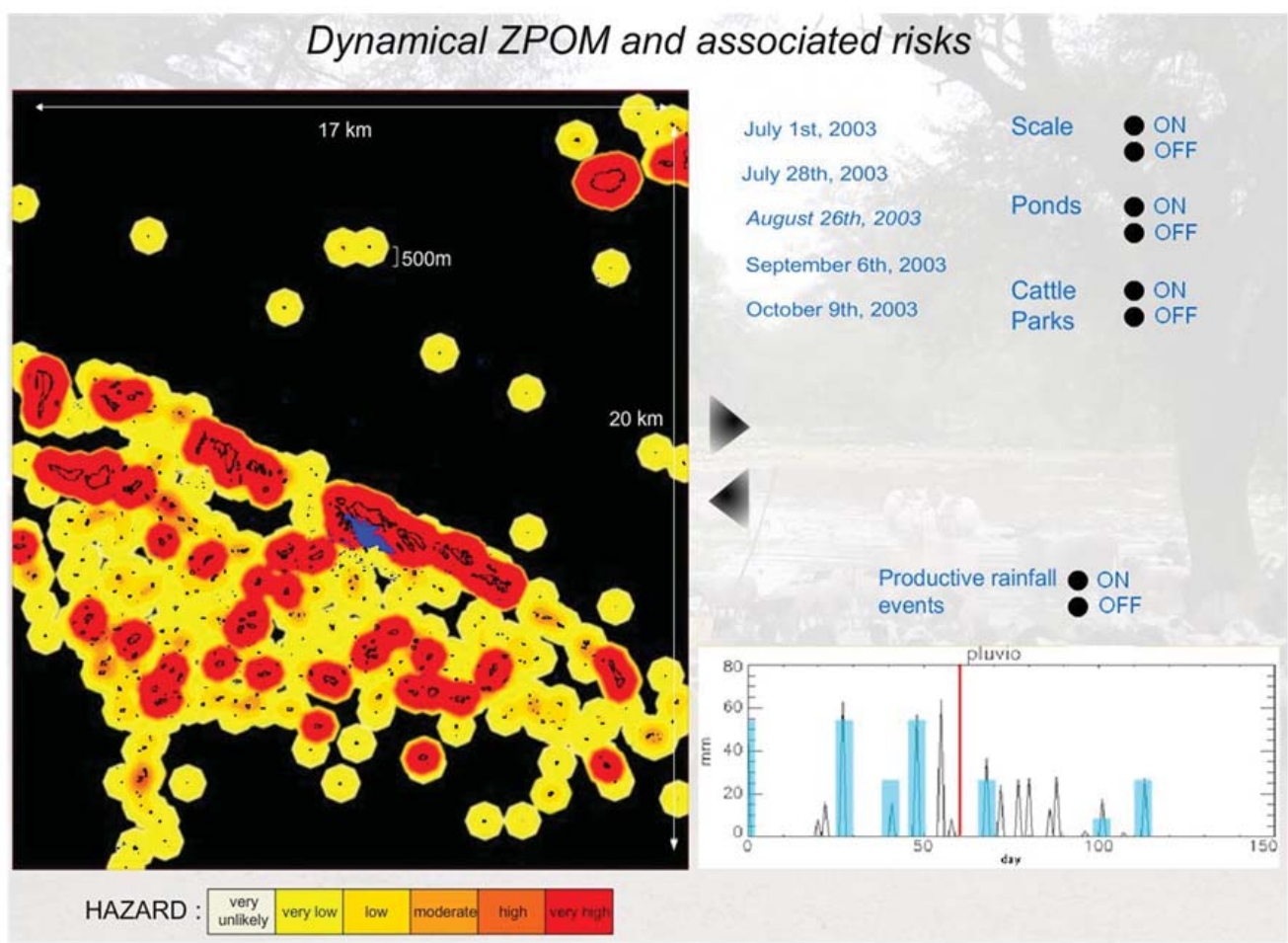

Fig. 6. Dynamic ZPOMs and risks. Dynamic ZPOMs with ranked risk (from very unlikely and very low in yellow, to very high in red, bottom scale) and ponds distribution (in blue) during the 2003 rainy season. From the hyperlinked Figure in the on-line paper, by clicking on the two fat black arrows, animated ZPOMs from productive rainfall (highlighted in blue, at the bottom right) are displayed (upper arrow is for forward motion, lower arrow for backward motion) along with the relative parks locations. The starting date is June 28, 2003. ZPOMS for specific date can also be displayed. The vertical red marker is for accurate time positioning on a daily basis. The results indicative of domestic animals vulnerability can be used as a tool for prediction of RVF environmental risks.

approach has been developed. It is to be implemented into an operational model, the main components of which can be listed as follows:

(i) identification of ponds by remote sensing (including the distribution, size and localization) using SPOT-5 products, TRMM-based timing and amount of rainfalls in association with on-site measurements (pond area, mean depth, etc.);

(ii) linkages with observed and modelled entomological data consisting of distribution and aggressiveness of the Ae. vexans vector;

(iii) estimation of risks (hazards and vulnerability) of animal hosts kept at night in the vicinity of ponds; and (iv) evaluation of the dynamic ZPOM and RVF environmental risks.

The above four steps can be used in an operational mode when the location of the pond(s) has been determined within the given eco-zones and when the presence and aggressiveness of the vectors have been evaluated. The socio-economic risks can thus be anticipated based on statistical evaluation of the seasonal rainfalls which can be done already a few months prior to the rainy season (seasonal forecasts). Then, strategic displacement of the fenced-in areas during a rainy season can be managed so that the local risks decrease. To see if this reasoning holds also for the longer term, we intend to analyze the inter-annual variability of exposure to vector 
bites for the 2003-2008 period using the methodology presented in this paper.

Climatic and environmental risks are necessary conditions for the RVF virus to circulate and be transmitted. This new, methodological approach which can be used in quasi real-time, is to be linked with biological modelling of virus transmission and circulation as well as with classical epidemiological models. Ultimately, the fully integrated approach should help understanding the mechanisms leading to potential RVF epidemics and improve related EWS. The physical and biological mechanisms are meant to be applied to other diseases in other places with different environments.

\section{Acknowledgments}

The authors would like to thank Dr. Antonio Güell, Head of the Application and Valorization department at CNES, for his unconditional support. Y.M. Tourre would like to thank Dr. Philippe Dandin and Dr. Mike Purdy, Directors of the Climatology Department at METEOFrance and of the LDEO of Columbia University, respectively, for facilitating this applied research. This is an LDEO contribution \# 7244.

\section{References}

Bâ Y, Diallo D, Kebe CMF, Dia I, Diallo M, 2005. Aspects of bio-ecology of two Rift Valley fever virus vectors in Senegal (West Africa): Aedes vexans and Culex poicilipes (Diptera: Culicidae). J Med Entomol 42, 739-750.

Bicout DJ, 2001. Modélisation sur la fièvre de la Vallée du Rift. Compte Rendu de la Rencontre. Version 2. Nimes (France), 8-9 February 2001, p. 13.

Bicout DJ, Porphyre T, Ndione J-A, Sabatier P, 2003. Modelling abundance of Aedes and Culex spp. in rain fed ponds in Barkédji, Senegal. ISVEE Proceedings of the 10th International Symposium on Veterinary Epidemiology and Economics.

Chevalier V, Lancelot R, Thiongane Y, Sall B, Diaïté A, Mondet B, 2004. Rift Valley fever in small ruminants. Emerg Infect Dis 11, 1693-1700.

CNES, 2008. Method for tele-epidemiology (Méthode pour la télé-épidémiologie). Patent pending.

Diallo M, Nabeth P, Bâ K, Sall AA, Bâ Y, Mondo M, Girault L, Abdalahi MO, Mathiot C, 2005. Mosquitoe vectors of the 1998-1999 outbreak of Rift Valley fever and other arboviruses (Bagaza, Sanar, Wesselsbron and West Nile) in Mauritania and Senegal. Med Vet Entomol 19, 119-126.

Fontenille D, Traoré-Lamizana M, Diallo M, Thonnon J, Digoutte J-P, Zeller HG, 1998. New vectors of Rift Valley fever in West Africa. Emerg Infect Dis 4, 289-293.

Lacaux J-P, Tourre YM, Vignolles C, Ndione J-A, Lafaye M, 2007. Classification of ponds from high-spatial resolution remote sensing: application to Rift Valley fever epidemics in Senegal. Remote Sens Environ 106, 66-74.

Linthicum KJ, Anyamba A, Tucker CJ, Kelley PW, Myers MF, Peters CJ, 1999. Climate and satellite indicators to forecast Rift Valley epidemics in Kenya. Science 285, 397-400.

Lupi O, Tyring SK, 2003. Tropical dermatology: viral tropical diseases. J Am Acad Dermatol 49, 979-1000.

Meegan J, Le Guenno B, Ksiazek T, Jouan A, Knauert F, Digoutte JP, Peters CJ, 1989. Rapid diagnosis of Rift Valley fever: a comparison of methods for the direct detection of viral antigen in human sera. Res Virol, 140, 59-65.

Mondet B, Diaité A, Fall AG, Chevalier V, 2005a. Relations entre la pluviométrie et le risque de transmission virale par les moustiques: cas du virus de la Rift Valley fever (RVF) dans le Ferlo (Sénégal). Environ Ris Santé 4, 125-129.

Mondet B, Diaité A, Ndione J-A, Fall AG, Chevalier V, Lancelot R, Ndiaye M, Ponçon N, 2005b. Rainfall patterns and population dynamics of Aedes (Aedimorphus) vexans arabiensis, Patton 1905 (Diptera: Culicidae), a potential vector of Rift Valley fever virus in Senegal. J Vector Ecol 30, 102-106.

Ndiaye PI, Bicout DJ, Mondet B, Sabatier P, 2006. Rainfall triggered dynamics of Aedes mosquito aggressiveness. J Theor Biol 243, 222-229.

Ndione J-A, Besancenot J-P, Lacaux J-P, Sabatier P, 2003. Environnement et épidémiologie de la fièvre de la vallée du Rift (FVR) dans le bassin inférieur du fleuve Sénégal. Environ Ris Santé 2, 1-7.

Ndione J-A, Diop M, Lacaux J-P, Gaye AT, 2008. Variabilité intra-saisonnière de la pluviométrie et émergence de la fièvre de la vallée du rift (FVR) dans la vallée du fleuve Sénégal: nouvelles considérations. Climatologie 5, 83-97.

Thomson MC, Doblas-Reyes FJ, Mason SJ, Hagedorn R, Connor SJ, Phindela T, Morse AP, Palmer T, 2006. Malaria 
early warnings based on seasonal climate forecasts from multi-model ensembles. Nature 439, 576-579.

Tourre YM, Lacaux J-P, Vignolles C, Ndione J-A, Lafaye M,
2008. Mapping of zones potentially occupied by Aedes vexans and Culex poicilipes mosquitoes, the main vectors of Rift Valley Fever in Senegal. Geospat Health 3, 69-79. 